\title{
Archivos y ciudadanía: el acceso a la información pública
}

\author{
André PORTO ANCONA LOPEZ \\ Universidade de Brasília, Faculdade de Ciência da Informação, \\ apalopez@gmail.com
}

Recibido: noviembre 2010

Aceptado: septiembre 2011

Resumen. Se trata de un artículo donde se propone discutir el papel activo de los archivos para el acceso a la información pública, considerándolos depositarios naturales de las pruebas de los actos administrativos y, por lo tanto, con un papel central en la agenda de la transparencia y de la ciudadanía El texto se plantea trabajar con los conceptos clave de los archivos y de los documentos de archivo con el propósito de discutir algunas de las relaciones existentes entre tales instituciones y la sociedad. El derecho al acceso a la información sobrepasa una comprensión más amplia del papel activo de los archivos, los cuales no se resumen a los meramente administrativos de Estado, sino también a los privados de interés público y social, tal como se ejemplifica con algunos casos brasileños. Las dimensiones activa y de prueba de los documentos de archivo están directamente relacionadas a sus cuatro características esenciales (organicidad, naturalidad, imparcialidad y autenticidad), tal como se trató de demostrar en otros ejemplos.

Palabras clave: archivos; ciudadanía; acceso a la información; documentos de archivo.

\section{Archives and citzenship: the access to public information}

\begin{abstract}
The essay intends to discuss the active role played by archives in order to provide access to public information, considering them as natural custodians of administrative acts evidences, therefore, with a central position on the agenda of transparency and citizenship. The text aims to deal with key concepts of archives and of archival documents in order to discuss some of the relationships among these institutions and society. The right of information access surpasses a broader understanding of the active role of the archives, which cannot be restricted to the administrative state archives but has also to consider private archives with public and social interests, as exemplified by some Brazilians cases. Active and proof dimensions of archival documents are directly related to the four essential characteristics (cohesiveness, naturalness, impartiality and authenticity), as is demonstrated with other examples.
\end{abstract}

Keywords: archives; citizenship; information access; archival documents. 


\section{INTRODUCCIÓN}

En la actualidad, la ampliación del concepto de documento se encuentra relativamente consolidada y cuenta además con una base suficientemente consensual. ${ }^{1}$ Muchos documentos originados por actores informales, son considerados hoy en día tan relevantes como lo son los tradicionales documentos oficiales para el registro de acciones y prueba de derechos. Inclusive documentos públicos semi sellados, y hasta los divulgados electrónicamente, de modo apenas referencial para documentos escritos y sellados, son considerados plenamente válidos. Pero por otra parte, tal ampliación del campo conceptual ha tenido un desdoblamiento bastante limitado en términos de prácticas efectivas de políticas públicas. La alfabetización, inclusive la digital, ${ }^{2}$ el impacto administrativo de los registros electrónicos, entre otras cuestiones, deben considerarse dentro del inventario actual de la ciudadanía y de la transparencia de las acciones públicas. El control informal de la administración de la esfera pública no se limita más a los medios masivos de comunicación. El ciudadano común puede, a través de la democratización del acceso a las nuevas tecnologías, funcionar como un importante contrapeso social y demandarle más transparencia a la administración pública. Mientras tanto, algunos antiguos problemas relativos a la organización de archivos continúan siendo urgentes en la nueva agenda. Sigue presente la necesidad de discusión sobre la relación existente entre los registros documentales (tradicionales y/o digitales) y la ciudadanía; así como la relación entre ciudadanía y derecho a la memoria. La primera tarea es dejar disponible, de modo amplio y cristalino, no solamente las grandes decisiones de la esfera pública, sino garantizar que el acceso también se haga efectivo con las informaciones que orientaron todo el proceso de toma de decisiones, así como los diferentes registros que compusieron el trámite.

\section{EL ACCESO A LA INFORMACIÓN}

No basta con que haya un registro sistemático de las acciones: es necesario que estén organizados y sean accesibles. Recientemente, en Brasil, en el ámbito de la cámara alta del poder legislativo (el Senado), se descubrieron y se divulgaron ampliamente a través de la prensa, una serie de actos vinculados a la gestión interna de aquél órgano que ni siquiera habían sido divulgados oficialmente. Los "actos secretos", como fueron denominados por la prensa, representaron una evidente provocación a los más elementales derechos de la sociedad de tener acceso a la

\footnotetext{
${ }^{1}$ Varios autores, como Jacques Le Goff, Michel Vovelle, entre otros, tratan la ampliación del campo conceptual del documento. En un texto anterior buscamos delinear mejor ese tema; véase Lopez (1996). (2005).

${ }^{2}$ Sobre esa cuestión, vinculada a la ciudadanía, véase por ejemplo, el estudio de Silva et. al.
} 
forma de utilización de los recursos públicos, oriundos de los impuestos. La no divulgación pública de tales decisiones confirma el carácter imparcial de los documentos de archivo, por un lado, y por otro, indica la necesidad de que los documentos de archivos del poder público tengan una política que se oriente hacia una amplia accesibilidad de los mismos, dejándose de lado apenas los casos de comprobada restricción a la información por motivo de fuerza mayor o que acarreen secuelas para el Estado -los argumentos de tal comprobación deberán ser públicos y plausibles de cuestionamiento.

El libre acceso del ciudadano a los diferentes registros que divulgan las acciones de la esfera pública, resulta insuficiente como para garantizar que la construcción de la memoria sea realizada a partir de elementos elegidos por el propio grupo. ${ }^{3}$ Los criterios de selección, así como los métodos de organización de los archivos y de acceso a los documentos, son portadores de carga ideológica y pueden condicionar la construcción de una memoria fundada en elementos exógenos. $\mathrm{Al}$ respecto de la seriedad y/o espíritu crítico del consultante interesado, tales procedimientos pueden propiciar una visión restringida de la historia, así como construir un discurso auto legitimador, que se proponga justificar decisiones tomadas subvirtiendo el principio de la gobernabilidad, al funcionar como una lente que, aparentemente, no comprometerá la transparencia pero que podrá, efectivamente, distorsionar la imagen. De este modo, resulta fundamental el desarrollo de metodologías propias que enfoquen no sólo la particularidad de las entidades generadoras de archivos, sino también las especificidades de los documentos dentro de ese universo que, cada vez más, está ampliándose. La transparencia de los criterios de generación, organización, selección y disposición de registros se vuelve primordial para que el ciudadano pueda establecer límites de análisis, interpretación y uso de informaciones y documentos.

\section{EL PAPEL ACTIVO DE LOS ARCHIVOS}

\subsection{ARCHIVOS ADMINISTRATIVOS DEL ESTADO}

Es preciso repensar el papel que los archivos ejercen frente a la sociedad, destacando que no se limitan a desempeñar una función pasiva, a modo de repositorios del pasado y de insumos para la constitución de múltiples visiones de la historia y la construcción de innumerables memorias. Los archivos, como reflejo de acciones administrativas, por cierto desempeñarán dichas funciones. Sin embargo,

\footnotetext{
${ }^{3} \mathrm{Al}$ referirnos a la memoria pensamos, sobre todo, en memoria como selección y construcción dinámica realizada por un grupo social. La clásica obra de Maurice Halbwachs (1990), en un texto publicado a partir de sus archivos personales de la década de 1950, introduce conceptos fundamentales en ese sentido. Para una discusión conceptual de la relación entre memoria e historia, véase Meneses (1992 e 1998), Nora (1993), entre otros tantos.
} 
justamente por ser depositarios naturales de las pruebas de los actos administrativos, ocupan un papel central en la agenda de la transparencia y la ciudadanía. Indicativo de esta distinción es el espacio destinado a los archivos en las organizaciones y en las administraciones públicas. Cuando los archivos son entendidos apenas como pasivos repositorios del pasado, generalmente se encuentran localizados en sectores más cercanos a la realización de acciones culturales, muchas veces confundiéndoseles, o siendo indistintamente mezclados, con bibliotecas y/o museos. En las situaciones en las que los archivos desempeñan un papel activo como soporte para la toma de decisiones y como guardián de los registros de las acciones ejecutadas, ese tipo de organismo suele ligarse a las esferas administrativas decisorias y/o directamente al comando del primer escalón. Tal proximidad, por sí misma, no garantiza que la gobernabilidad sea efectiva, pero lo dota al archivo de eficacia e importancia estratégica. No por casualidad los archivos nacionales, en la conturbada historia latinoamericana, nunca tuvieron que pasar por una situación similar a la de Lituania, cuando concluyó el régimen soviético. El edificio de su archivo nacional, en Vilinus, se vio cercado por tanques soviéticos durante un año y medio, mientras que archivistas simpáticos al nuevo Estado, proseguían sus quehaceres dentro del edificio con total normalidad, con el fin de que los trabajos no se vieran interrumpidos. ${ }^{4}$ El impase no se refería más a la integridad de la antigua Unión Soviética versus la independencia de Lituania, aspecto que ya había sido resuelto. Se refería al control de los registros de las acciones del Estado. Ese episodio ilustra muy bien que los archivos pueden tener un papel preponderante en la eficiencia de las acciones del Estado. También apunta la necesidad de que haya un control efectivo y transparente de la sociedad sobre esa institución. Cuanto más transparente se disponga a ser una administración, más próxima a la esfera decisoria estará el archivo.

\subsection{ARCHIVOS PRIVADOS DE INTERÉS SOCIAL}

Igualmente importantes son los archivos privados, sobre todo los que están más relacionados con la sociedad, tales como los de empresas prestadoras de servicios públicos, archivos personales de personajes marcantes de la vida nacional, los de asociaciones (sociales, económicas, culturales), sindicatos, gremios políticos, etc. A respecto del interés público se hace necesario indicar que la autonomía privada de los registros de tales entes se mantenga preservada, cabiéndole al Estado, cuando sea el caso, un papel de facilitador de la preservación, organización y acceso a tales acervos. Como actores marcantes en la vida nacional, el pleno ejercicio de la

\footnotetext{
${ }^{4}$ Ese acontecimiento fue descripto por Van Rossum (1997), quien realizó una importante caracterización de los archivos de Europa Oriental, cuando ocurrió la desagregación del régimen soviético.
} 
ciudadanía pasa, en cierta medida, por el acceso a los registros de los archivos privados, los cuales componen, en verdad, un campus documental muy heterogéneo.

\subsection{EJEMPLO: AGRUPAMIENTOS POLÍTICO-PARTIDARIOS CLANDESTINOS DEL PERÍODO DICTATORIAL BRASILEÑO (1964-89)}

Destacamos, a modo de ejemplo, un universo en el cual estas características lograron proporciones extremas: los agrupamientos político-partidarios clandestinos del período dictatorial brasileño (1964-1989). Las organizaciones políticopartidarias clandestinas representan, por su propia condición de ilegalidad, individuos que encontraron retenida, lo que ya era una restricta ciudadanía política. Esos ciudadanos, a pesar de la interdicción formal, continuaron actuantes en el cuadro político, ejerciendo un papel relevante en la sociedad. Su influencia se hizo sentir tanto directa como indirectamente. En el primer caso, tenemos las consecuencias inmediatas del papel que desempeñaron como actores políticos (aunque no autorizados legalmente); en el segundo, su acción puede notarse en las respuestas que provocaron en la opinión pública -particularmente en los medios de comunicación masivos- y en las alteraciones políticas del régimen, tales como decretos, leyes y otras medidas, cuyo objetivo principal era cercenar (e impedir), si fuera posible, la acción de dichos actores. Debe destacarse que los partidos clandestinos siguieron desempeñando un papel activo dentro del sistema partidario, sea englobados por otros lemas partidarios, sea actuando dentro del movimiento social. El hecho de que un partido no quisiera (o no pudiera) presentar candidatos en elecciones, no lo inviabilizaba como partido. La organización y el estudio de la producción documental de esas agrupaciones están cubiertos por una especie de carácter de revisión histórica, en la medida en que proponen permitir la construcción de otra memoria y de recuperar el papel político que ellas desempeñaron. Esto se contrapone a un reconocimiento académico superficial, muchas veces underground, de la acción de tales actores, minimizándose la importancia de sus actividades dentro del proceso político global.

Las organizaciones político-partidarias presentan características propias que tienden a perderse en los esquemas universalizantes sugeridos por la bibliografía disponible al respecto. Tales características tienden a diluirse cuando se prioriza el aspecto formal de los documentos. Debemos considerar y discutir los elementos informales presentes en la producción documental de naturaleza política. Muchas veces, en ese tipo de entidad, los documentos fueron producidos, en principio, sin ningún tipo de reglamentación, normativización oficial o preocupación jurídicolegal. Tales agrupaciones presentan, entre las funciones formales (o normativizadas) y las que son efectivamente desarrolladas, un desfasaje muy superior al presentado por entidades legalizadas, insertas en el sistema partidario formal. No obstante, debe destacarse que muchas veces las agrupaciones legales ejercen acti- 
vidades que van más allá de su fachada normativo/formal. En ese sentido, el análisis de las asociaciones clandestinas se justifica no sólo para la comprensión de las actividades informales de las agrupaciones ilegales, sino también para la de las actividades informales (o extra-legales) de los partidos legalmente constituidos.

\subsection{EL ARCHIVO COMO UN CONJUNTO DE PRUEBAS Y ACCIONES}

La organización archivística siempre debe tratar de retratar las actividades reales de las instituciones y, en la medida de lo posible, ser un fiel espejo de ellas para que exista una contextualización de la producción documental, según los modelos definidos por la propia dinámica administrativa de la organización. La dificultad se encuentra en el hecho de que las funciones realmente desarrolladas por una institución -especialmente en los partidos clandestinos, ${ }^{5}$ pero también en los oficiales e inclusive en los órganos estatales-son diferentes de las registradas o explicitadas oficialmente. De esta manera, la tarea del archivista es la de tratar de comprender lo mejor posible la "misión" y la "visión" de la organización y la "máquina" administrativa, tomando las debidas precauciones de utilizar las funciones explicitadas formalmente apenas como referentes pero nunca como reflejo absoluto de la realidad; o sea, tratar de realizar la mediación entre lo que se pretendía desempeñar (o lo que se afirmaba como objetivo hipotético) y lo que de hecho fue realizado (registrado por los documentos de archivo). El propio Estado, a pesar de la existencia de una normativización jurídica bastante detallada, muchas veces trasciende las fronteras formales con acciones que van más allá de los límites previamente definidos. En determinadas circunstancias, como por ejemplo durante los períodos dictatoriales, las informaciones sobre las actividades desarrolladas son escasas y, además, se ocultan deliberadamente las actividades ilegales mediante una mínima producción de documentos comprometedores y la sistemática eliminación posterior de los mismos.

Si un documento, entendido genéricamente, es cualquier tipo de información fijada en un soporte, el de archivo resulta más específico por tratarse, necesariamente, del producto de una voluntad administrativa. Contextualiza su propia génesis administrativa y los vínculos directos con los procesos y las funciones responsables por su existencia. El concepto de archivo demanda aún, la acción deliberada de preservar los documentos después de cumplirse las actividades para los cuales fueron creados. ${ }^{6}$ De este modo, el consultante debe ser capaz de, a partir de las informaciones que se encuentren disponibles a través del propio archivo, identifi-

${ }^{5}$ Bajo esta perspectiva, la definición de partido político utilizada por Umberto Cerroni (1982, p.13), a pesar de ser amplia, nos resulta más adecuada: "conjunto que puede definirse como una máquina organizativa y un programa político estructurado y articulado".

6 Para el Dicionário de terminologia arquivística (1996, p.5), el archivo es tanto ese conjunto de documentos, como la entidad responsable por él. 
car dicha voluntad administrativa, o sea: el contexto de producción. Para ello, los documentos deben traer informaciones relativas a "quién", "cuándo", "cómo" y, principalmente, "por qué" fueron producidos y guardados como registros significativos. Para que de hecho los archivos sean herramientas de la transparencia administrativa, tal comprensión debe quedar claramente evidenciada para el consultante. El archivo es un conjunto sistematizado de pruebas de acciones, que abarca, en principio, toda la existencia de su titular; la Archivología se preocupará por entender tanto los motivos que llevaron a determinado individuo, o institución, a producir un dado documento, como las razones de su preservación. La importancia del contexto de producción documental para comprender la información vehiculada por el documento fue destacada por Paola Carucci:

"evidentemente el documento interesa por su contenido, por las informaciones que transmite. Inclusive, las noticias que en él son representadas o descriptas requieren, por parte de quien las adapta a las capacidades técnicas, que sean traducidas en cánones de representación, los cuales, a su vez, pueden constituirse en objeto de análisis, transformándose en testigos directos de la actividad del documentar" (CARUCCI, 1987, p.14).

El interés por la contextualización archivística recae sobre las actividades del productor, expresadas a través de documentos, los cuales mantienen una relación de indicialidad con las actividades. No basta dejar disponibles las informaciones del titular si éstas carecen de los atributos de prueba. La comprensión de las acciones administrativas supera la divulgación del funcionamiento de la esfera decisoria y de los procedimientos y documentos que sustentan y consolidan tales acciones. Por lo tanto, el objetivo es entender al productor de los documentos y no apenas la información que éstos presentan. Según Luciana Duranti (1996, p. 61), en los documentos modernos, el fraccionamiento del trámite y la subdivisión de las informaciones aparecen como características principales. El documento, que otrora era completo, es decir, presentaba todos los datos referidos al trámite que lo produjo, hoy en día presenta esas informaciones subdivididas en múltiples documentos, en un gran proceso. De este modo, la comprensión del sentido institucional de un documento moderno abarca también el conocimiento de su trámite administrativo y las relaciones que él mismo mantiene con sus sucesores y antecesores. Con la profusión de los medios electrónicos, esa situación se vuelve más compleja. La transparencia se verá perjudicada si, por ejemplo, un proyecto de ley se ve dividido públicamente y las informaciones relativas a su tramitación y posible información sobre ellos, en el caso de procedimientos reservados y/o sigilosos necesarios para entender la tramitación no se hace viable, entonces no será posible entender plenamente el proyecto. 


\section{ESPECIFICIDADES DE LOS DOCUMENTOS DE ARCHIVO}

Las especificidades de los archivos pueden sintetizarse en cuatro características principales: organicidad, naturalidad, autenticidad e imparcialidad. Dichas características fueron conceptualmente forjadas por el archivista británico Sir Hilary Jenkinson (1965) en la clásica obra publicada en 1922 y revisadas, posteriormente, por Luciana Duranti (1994). Es importante destacar que tales aspectos se refieren esencialmente a los documentos en sí y no a las actividades que los generaron ni tampoco a sus productores ni a su utilización, sea por éstos últimos, sea por los investigadores en momentos posteriores.

\subsection{ORGANICIDAD Y NATURALIDAD}

Sobre la organicidad y la naturalidad (o serialidad) corresponde destacar que: Los archivos no son documentos relevados artificialmente [...] sin embargo, están acumulados naturalmente [...] para los objetivos prácticos de la administración." (PUBLIC RECORD OFFICE, 1949, p.2).

El hecho de que los documentos de archivo [...] se acumulen natural, progresiva y constantemente [...] les garantiza una cohesión espontánea y estructurada. [Siendo que] la unicidad entra como corolario de esta última característica." (DURANTI,1994, p.335).

Dentro del contexto del acervo, la organicidad de los documentos en relación a su producción establece las unidades básicas del archivo: las series. Son conjuntos de documentos de un mismo titular, referentes a una misma actividad, pertenecientes a la misma especie documental. Así, debería ser ofrecida al consultante una búsqueda por las funciones del titular antes de tornar disponibles temas predefinidos por el archivo, impositiva y subjetivamente, como de interés público. En la organización archivística, la información inmediata vehiculada por el documento pierde importancia para las informaciones del contexto administrativo.

El documento de archivo debidamente contextualizado tiene su polisemia reducida y, por esa razón y en un primer momento, orienta las posibilidades de análisis de la información, al establecer las prioridades según la organicidad. Precisamente, ese direccionamiento previo nos permite, a posteriori, sostener la capacidad de comprensión y análisis del documento, admitiendo, inclusive la inserción de las mismas informaciones primarias, si bien con mayor inteligibilidad. Esa aparente contradicción le asegura al documento de archivo -cuando éste está debidamente organizado según su productor y sus actividades- la máxima ampliación de su potencialidad informativa. Este aumento ofrece una sólida base para que la ambigüedad desaparezca con su uso posterior (por el consultante, por ejemplo), ampliando las posibilidades analíticas. La adopción de modelos y elementos formulares por los documentos de archivo, transpuestos a la organización archivística, también auxilian en la reducción de la ambigüedad, presente en cualquier tipo de 
documento no contextualizado, multiplicando así sus posibilidades de utilización e interpretación. El típico documento de archivo es portador de una gran elocuencia, indicando claramente cuál es su finalidad. Precisamente, esa elocuencia permite comprender su sentido y los motivos por los cuáles fue preservado.

El típico documento de archivo es producido en serie, justamente por ser fruto de actividades rutinarias, correlacionándose a otros documentos que fueron creados durante el ejercicio de las mismas funciones. Tales documentos, diferentes en sus individualidades por referirse a informaciones específicas, son similares en el formato y en el papel desempeñado en cumplimiento de las actividades de su productor. Ese documento también puede modificarse a lo largo de su existencia, asumiendo funciones diferenciadas. Inclusive puede tornarse documento de archivos distintos, a pesar de contener una información primaria prácticamente idéntica.

El ejemplo presentado a continuación ilustra bien la necesidad de contextualización archivística para la plena comprensión del documento: ${ }^{7}$

Figura 1: Tarjeta de control de préstamos de la Biblioteca Pública Municipal de Maringá, copiado por la policía política brasileña durante el período dictatorial.

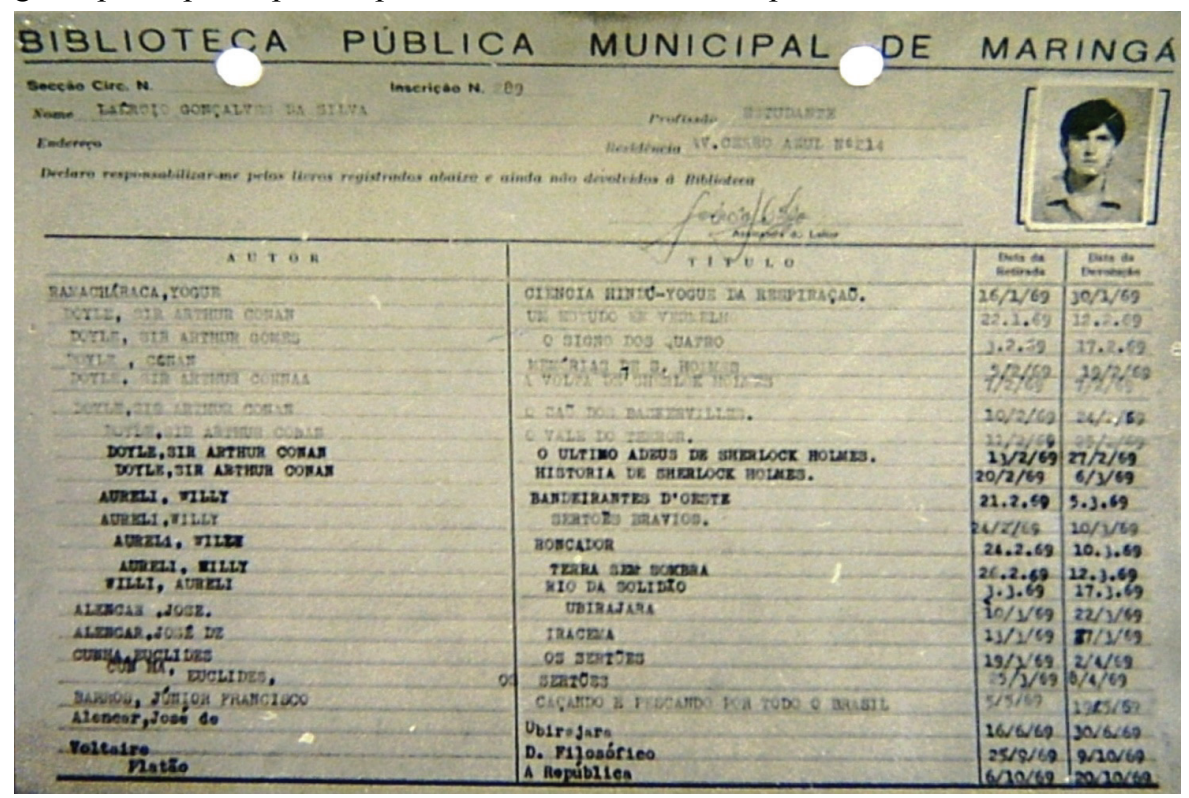

Fuente: Departamento Estatal de Archivo Público. Archivo Público de Paraná. Fondo Jefatura del Orden Político y Social. Dosier "Jefatura de Policía de Maringá (Antigua)". Caja 62, carpeta 556. (Digifoto, 2006, foto 40).

Este documento, tanto en la actualidad como en el pasado, representa un registro de las actividades de investigación política durante el período de la dictadura militar

${ }^{7}$ Ejemplo extraído de Lopez (2009). 
en Brasil. En sus orígenes fue, ciertamente, una ficha de biblioteca, usada para controlar préstamos de libros pero a través de la acción de la Jefatura de Orden Política y Social de Paraná (DOPS/PR $)^{8}$, se transformó en otro documento, de otra organización, con otras funciones administrativas y comprobatorias. El punto principal es el hecho de que ninguna de esas modificaciones quedó explícitamente registrada en el documento. La contextualización es la única pista posible que determina el verdadero papel del documento y que permite crear los vínculos con el productor archivístico. Sin la contextualización, la violación sistemática de la privacidad de los ciudadanos jamás podría probarse. Nadie podría imaginarse que alguien podía ser considerado sospechoso de atentar contra el gobierno brasileño, por el simple hecho leer Platón.

\subsection{AUTENTICIDAD E IMPARCIALIDAD}

Sobre la autenticidad y la imparcialidad, Duranti (1994, p.334-335) explica que:

Los archivos son inherentemente verídicos.

[...] la imparcialidad es una característica de los documentos de archivo, no de sus creadores, quienes son naturalmente parciales por sus propios intereses.

[Los archivos] son creados como verosimiles y confiables para quien los necesita para actuar. Se mantienen con garantías apropiadas para acciones futuras y para información. [...] Y son preservados por sus productores -o sucesores - a modo de registro de las actividades pasadas.

La autenticidad está vinculada al proceso de generación del documento y se diferencia de la veracidad, la que se refiere a la calidad de las informaciones. El documento auténtico es el que efectivamente es lo que dice ser y cumple la función para la cual fue creado, aunque contenga informaciones falsas. En un documento considerado aisladamente, la veracidad tiende a confundirse con la autenticidad, dado que no existirán datos para determinar el contexto del documento, siendo imposible determinar su autenticidad. Cuando somos capaces de correlacionar orgánicamente un documento con las demás actividades de su productor institucional -en vez de abordarlo de modo aislado- la veracidad se separa totalmente de la autenticidad. En el caso de una información falsificada, al desprendérselo del contexto se comprometerá su uso, y será considerado falso, también. En caso de que esté contextualizado archivísticamente, la percepción de la falsificación de informaciones no perjudicará su uso, pues la contextualización permitirá una mejor comprensión del documento y de los motivos que llevaron a su produc-

${ }^{8}$ Sobre la acción de DOPS/PR y la producción de documentos de archivo relativos a Maringá, ver Lopez et al. (2008). 
tor a la adulteración pudiéndose, inclusive, obligarlo a responsabilizarse por el acto cometido.

Recientemente hubo una denuncia en Brasil sobre un decreto presidencial de 1978 que fue fraudado, causándole serios daños económicos a los trabajadores del gobierno que habían optado por un plan de demisión voluntaria. En relación a la ciudadanía, el episodio resulta curioso no sólo en lo que se refiere al hecho de lidiar con un documento de archivo cuyo fraude fue descubierto por un diputado, sino también porque la divulgación y el acceso a la información fueron realizados principalmente por los vehículos masivos de información, formales (prensa) e informales (Internet). Después de la difusión de la noticia a través de la prensa, ${ }^{9}$ el documento adulterado y la reproducción del hecho quedaron ampliamente disponibles en internet, inclusive en un servicio de comunicación del propio Ministerio de Planeamiento, ${ }^{10}$ órgano responsable por el cálculo y por la autorización de pago de remuneraciones a los empleados públicos federales. En todas las fuentes localizadas en Internet, inclusive en las oficiales, siempre aparecen los créditos para el primer periódico que divulgó el hecho, como si un error del Estado fuese algo ajeno a su propia esfera decisoria. Hasta el momento nosotros, meros ciudadanos, no tenemos mayores informaciones sobre el destino de las responsabilidades del fraude. La transmisión de noticias se limita a los procedimientos legales en curso que intentan revertir los efectos de la falsificación del documento. El decreto fraudado indica la acción del Estado, así como el propio fraude en sí, apenas detectado por un análisis de autenticidad, que identificó la ausencia del sello oficial, además de la adulteración del texto realizada con una máquina de escribir diferente a la original. Las tablas mostradas a continuación ilustran algunos aspectos exógenos que evidencian el fraude:

\footnotetext{
${ }^{9}$ Publicado el 06.set.2009 en el periódico Correio Braziliense. Una versión electrónica de la noticia se encuentra disponible en:

$<$ http://www.correiobraziliense.com.br/app/noticia182/2009/09/06/politica,i=140316/RASURA + EM+DECRETO+ASSINADO+POR+GEISEL+TERIA+REDUZIDO+A+UM+TERCO+BEN EFICIOS+PAGOS+EM+PROGRAMAS+DE+DEMISSAO.shtml $>$, último acceso: 28.Set.2009.

${ }^{10}$ Ver la página de selección de noticias realizada por la Asesoría de Comunicación del Gabinete del Ministro en:

https://conteudoclippingmp.planejamento.gov.br/cadastros/noticias/2009/9/7/rasura-emdecreto-assinado-ha-31-anos-lesa-os-servidores, último acceso: 28.Set.2009.
} 
Tabla 1: Reproducción del documento oficial borroneado, con adulteración del $§ 2$.

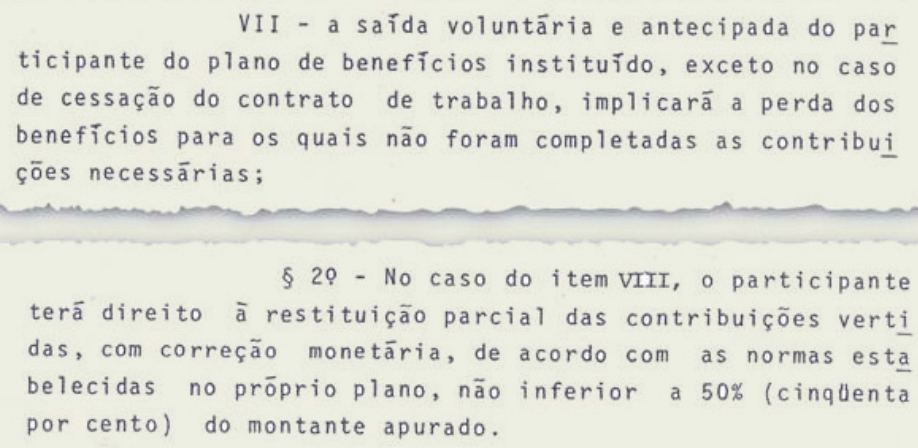

Fuente: adaptación de reproducción del documento provista por la página web de la Asociación de los Servidores del Instituto Nacional de Metrología, Normalización y Calidad Industrial (2009).

Tabla 2: Destaques y ampliación de detalles del decreto borroneado.

Texto original: fuente semejante a la Arial, con serifias tenues en los números romanos y con coma redondeada.

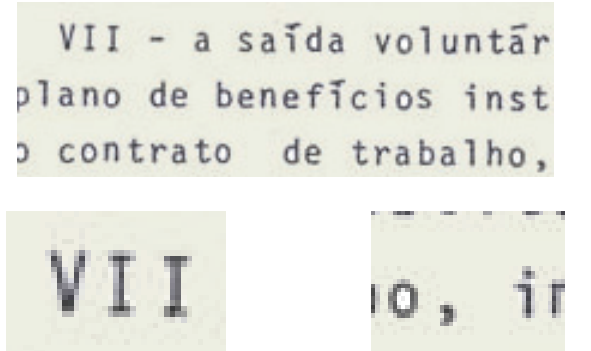

Ítem adulterado ("VIII,"): espacios más estrechos, presencia de serifias acentuadas en los números romanos y con coma recta.

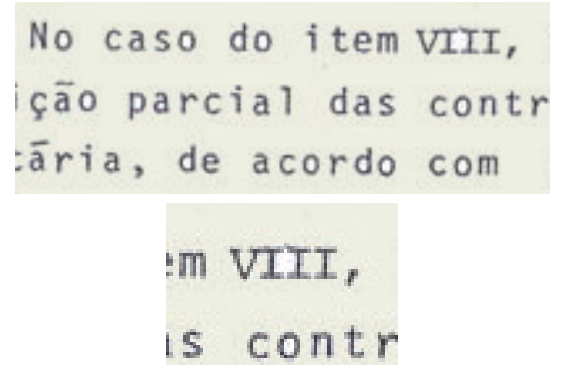

Fuente: adaptación de reproducción del documento provista por la página web de la Asociación de los Servidores del Instituto Nacional de Metrología, Normalización y Calidad Industrial (2009).

La imparcialidad es una característica que, a simple vista, parece inadmisible para quienes no están acostumbrados con los archivos. Pero es una característica importante para que los archivos resultantes del poder público puedan ejercer su función ciudadana, en el sentido de reflejarle a la sociedad las actividades que efectivamente fueron ejecutadas por el Estado. La comprensión de la contextualización archivística permite entender mejor qué es la imparcialidad, dentro del ámbito archivístico, pues deriva de la propia naturaleza y de las condiciones de creación de los documentos, los cuales e independientemente de las intenciones e ideologías de sus creadores -y del análisis e interpretación de los consultantes- 
son, antes que nada, los frutos, medios y testimonios directos de determinadas funciones, actos y actividades realizadas por sus productores.

La imparcialidad de los documentos de archivo puede ejemplificarse con el proyecto Brasil Nunca Más, llevado a cabo por la Arquidiócesis de São Paulo $(1986)^{11}$. Dicho proyecto representó el esfuerzo y la acción política que permitieron, de una vez para siempre, desenmascarar los aparatos usados por la represión política, a través de los documentos producidos por el propio Estado (ARQUIDIÓCESIS DE SÃo PAULO, 1986, P. 21-27). Utilizando los procesos judiciales realizados por el propio régimen militar, el proyecto promovió una amplia denuncia sobre la tortura y las prácticas de excepción adoptadas por el régimen militar brasileño. Los documentos recolectados por Brasil Nunca Más abarcan un amplio espectro cronológico. Muchos presentan la particularidad de ser documentos "subversivos", recogidos y depositados por los organismos de represión política. Característica que, paradójicamente, garantiza una correcta contextualización de los mismos, pues las entidades que los produjeron no tuvieron la posibilidad de eliminarlos o de "camuflar" sus objetivos. La fidelidad de los registros documentales de las actividades de opositores al régimen pos 1964, proporcionó apoyo legal para el cercenamiento de sus derechos políticos. Igualmente, documentos producidos por la dictadura registraron la anulación de los derechos políticos y sirvieron como base para que el proyecto pudiera denunciar abusos cometidos por el régimen militar. Esto equivale a afirmar que los mismos documentos que sirvieron para los intereses del gobierno militar se volvieron la base concreta de denuncia de las mismas actividades.

La producción de un documento -tal como se observa en el caso de Brasil: nunca más- al contrario de su uso en investigación, no es consciente ni inconsciente, sino natural y espontánea. El carácter "objetivo" de la producción documental, le restringe el uso y/o interpretación ideológica a los consultantes y a los propios individuos y organizaciones que produjeron los documentos. Le cabe a los archivos la organización de tales registros de acuerdo con el contexto de producción. A su vez, le compete al ciudadano promover la crítica de dicho contexto y de las acciones de los productores, y no a los documentos en sí. El documento de archivo, como reflejo directo de su productor, registra neutralmente los hechos y los actos de su creador -aunque el productor nunca sea neutro-. Luciana Duranti (1994, p.51) entiende que la imparcialidad de los documentos archivísticos [...] no significa que los lectores de los documentos deban creer que ellos reproducen los hechos y los actos de los cuales forman parte: el contexto más amplio de la actividad generadora de los documentos y el ambiente cultural en el cual sus intérpretes viven, son factores

${ }^{11}$ La importancia archivística de dicho proyecto fue analizada en un trabajo anterior; ver Lopez (1999). 
esenciales para la comprensión de la verdad que puede extraerse de los documentos.

\section{PRESERVACIÓN DE ARCHIVOS Y CIUDADANÍA}

La inclusión de los archivos dentro de la agenda de la transparencia, trata de sumar esfuerzos a las directrices pregonadas por la UNESCO sobre el desarrollo y la promoción de la información gubernamental de dominio público, según lo sistematizado por Paul Uhlir (2006) ${ }^{12}$. Un amplio programa de preservación de los registros de las acciones más significativas de la vida social sólo podrá ser efectivo si incluye la discusión del control social de los archivos. Además de las acciones de preservación de los registros, no debe pleitearse solamente el acceso indeterminado a las informaciones de interés público. Más interesante resulta promover que se haga efectivo el acceso de documentos e informaciones archivísticamente contextualizados, de modo tal que los ciudadanos se vean favorecidos con informaciones archivísticas sistemáticas, estructuradas y consistentes, reflejo de las acciones administrativas efectivamente desempeñadas por las organizaciones y por el Estado.

La efectiva transparencia es brindar a los ciudadanos con informaciones archivísticas sistemáticas, estructuradas y consistentes, reflejo de las acciones administrativas efectivamente desempeñadas por las organizaciones y por el Estado. La institución responsable por eso llamase archivo.

\section{BIBLIOGRÁFIA}

ARQUIDIOCESE DE SÃO PAULO. Brasil: nunca mais. $18^{\mathrm{a}}$ ed. Petrópolis: Vozes, 1986.

ASSOCIAÇÃO DOS SERVIDORES DO INSTITUTO NACIONAL DE METROLOGIA, NORMALIZAÇÃO E QUALIDADE INDUSTRIAL (INMETRO). Erro histórico contra servidores, 2009. Disponible en $<$ http://www.asmetro.org.br/pdfs2009/setembro/Erro\%20hist.pdf $>$, último acceso: 08. Set. 2009.

CARUCCI, Paola. Il documento contemporaneo: diplomatica e criteri di edizione.

Roma: La Nuova Italia Scientifica, 1987. (Beni Culturali, 1).

CERRONI, Umberto. Teoria do partido politico. Trad. Marco Aurélio Nogueira e Sílvia Anette Kneip. São Paulo: LECH, 1982. (História e Política, 15).

DICIONÁRIO de terminologia arquivistica. São Paulo: AAB-SP; Secretaria de Estado da Cultura, 1996.

\footnotetext{
${ }^{12}$ En el mismo sentido, cabe citar el detallado estudio de Sérgio Albite Silva (2008) sobre la ausencia de políticas públicas de preservación de la información archivística gubernamental en Brasil.
} 
DIGIFOTO: mapeamento e digitalização de documentos fotográficos de Maringá e Região. Brasília: UnB/ Maringá: UEM, 2006. Base de datos en Microsoft Access.

DURANTI, Luciana. "The concept of appraisal and archival theory". The american archivist. The Society of American Archivists, Chicago, v.57, $\mathrm{n}^{\circ} 2$, p.328344, 1994.

----. Diplomática: usos nuevos para una antigua ciencia. Trad. Manuel Vázquez. Carmona (Sevilla): S\&C, 1996. (Biblioteca Archivística, 5).

----. "Registros documentais contemporâneos como provas de ação". Trad. Adelina Novaes e Cruz. Estudos históricos. Rio de Janeiro, v.7, n 13, p.49-64, ene./jun. 1994.

HALBWACHS, Maurice. A memória coletiva. Trad. Laurent Léon Schaffter. São Paulo: Vértice, 1990. (Biblioteca Vértice, 21).

JENKINSON, Hilary. A Manual of archive administration. $2^{\mathrm{a}}$ ed. London: P. Lund, Humphries, 1965.

LOPEZ, André Porto Ancona. "Documento e história". En: MALERBA, J. (org.). A velha história: teoria, método e historiografia. Campinas: Papirus, 1996, p.15-36.

-----. Photographic document as image archival document. En: TEHNIČNI IN VSEBINSKI PROBLEMI KLASIČNEGA IN ELEKTRONSKEGA ARHIVIRANJA: referatov dopolnilnega izobraževanja s področij arhivistike, dokumentalistike in informatike v Radencih, 8, Maribor, 2009. Tehnični in Vsebinski Problemi ... Maribor: Pokrajinski Arhiv Maribor, 2009. p. 362-272. Disponible en $<$ http://eprints.rclis.org/15796/>. Último acceso: 12 set. 2009.

-----. Tipologia documental de partidos e associações políticas brasileiras. São Paulo: História Social UsP/ Loyola, 1999. (Tesis).

-----, PENTEADO, Matheus y NASCIMENTO, Luiz Miguel. "Norte do Paraná Sob vigilância: mapeamento e digitalização de fotografias produzidas pela DOPS-PR referentes à região Norte do Estado". Revista de História Regional, Ponta Grossa, 13, p.109-123, mayo 2008. Disponible en:

$<$ http://www.revistas.uepg.br/index.php?journal=rhr\&page=article\&op=view\& path $\% 5 \mathrm{~B} \% 5 \mathrm{D}=369>$, último acceso: 29 . set. 2009.

MENESES, Ulpiano Toledo Bezerra de. "História, cativa da memória?: para um mapeamento da memória no campo das Ciências Sociais". Revista do Instituto de Estudos Brasileiros. São Paulo, no 34, p.9-24, 1992.

-----. Memória, história e arquivo: reflexões para um tempo de transformações. En: CONGRESSO BRASILEIRO DE ARQUIVOLOGIA, $10^{\circ}$, 1994, São Pau1o. Anais do $10^{\circ}$ Congresso Brasileiro de Arquivologia: rumos e consolidação da arquivologia. São Paulo: Associação dos Arquivistas Brasileiros (Núcleo Regional de São Paulo), 1998. (CD-ROM).

NORA, Pierre. "Entre memória e história: a problemática dos lugares". Trad. Yara Aun Khoury. Projeto história. São Paulo, nº 10, p.7-28, 1993. 
PUBLIC RECORD OFFICE. Guide to the public records. Londres, 1949; p.2. Apud. DURANTI, Luciana. The concept of appraisal and archival theory. The american archivist. The Society of American Archivists, Chicago, v.57, $\mathrm{n}^{\mathrm{o}} 2$, p.328-344, 1994, p.335.

SILVA, Helena; JAMBEIRO, Othon; LIMA, Jussara y BRANDÃO, Marco Antônio. "Inclusão digital e educação para a competência informacional: uma questão de ética e cidadania". Ciência da Informação. Brasília, v.34, nº 1, p. 28-36, 2005.

SILVA, Sérgio Conde de Albite. A preservação da informação arquivística governamental na políticas públicas do Brasil. Rio de Janeiro: AAB/FAPERJ, 2008.

UHLIR, Paul F. Diretrizes políticas para o desenvolvimento e a promoção da informação governamental de domínio público. Brasília: UNESCO, 2006.

VAN ROSSUM, Leo. The former communist party archives in eastern Europe and Russia: a provisional assessment. Amsterdam: IISH, 1997. 